\title{
Governing data and data for governance: the everyday practice of Indigenous sovereignty
}

\section{Diane E Smith}

Not everything that can be counted counts,

And not everything that counts can be counted.

— Albert Einstein (according to the available data)

\section{Introduction}

The right of indigenous peoples to pursue development and cultural agendas in keeping with their self-determined aspirations and needs has been asserted by the United Nations Declaration on the Rights of Indigenous Peoples (UNDRIP). The reluctance of nation-states to recognise self-determination, let alone sovereignty, among the indigenous polities within their borders has been the subject of both critical commentary and advocacy. However, it is only recently that attention has been given to the kinds of internal expertise and institutions that are needed to mobilise the exercise of such rights by indigenous peoples. The argument of this chapter is accordingly twofold. First, that the foundation stone for translating indigenous rights into everyday practice now - as opposed to remaining an intangible future goal - is the collective ability of indigenous nations, 
communities and groups to self-govern, to make informed and internally accountable decisions about their current priorities and future direction. Second, for such effective self-governance to occur, indigenous peoples need access to a range of culturally relevant and accurate information about themselves; they need data they can trust.

A particular catalyst for much recent innovation by indigenous peoples in both these areas has been the imperative to decolonise the governance arrangements and the colonial data archives that have been externally created for and about indigenous peoples. As a consequence, a common set of interrelated questions is being considered by indigenous peoples across Canada, Australia, New Zealand and the United States (CANZUS), in spite of their having distinctive cultural traditions, histories and legal rights. These influential questions include:

- Who exactly is the collective 'self' in the self-determined and self-governing indigenous polity?

- Who are the intergenerational members of such polities on whose behalf data are to be collected and used?

- What kind of collective identity do indigenous people want to shape for themselves, now and into the future?

- What kinds of development - social, cultural and economicwill be pursued, and who should benefit from it?

- What role should indigenous culture play in collective decisions and solutions about these matters?

- What kinds of data will best support informed decision-making and effective solutions about these matters?

- And, importantly, who should have the authority to govern data on indigenous peoples - to collect, validate, interpret, own and use it?

These questions are considered here primarily through the lens of 'governance', meaning the institutions, relationships, processes and structures by which the collective will of a nation, clan, group or community is mobilised into sustained, organised action (Dodson \& Smith 2003; Smith 2005). Neither governance arrangements nor social collectivities are static; they are dynamic entities that may be modified and reconfigured according to changing conditions and needs. But for changes in governance and collective identity to be considered 
legitimate and so be supported by group members, 'knowledgeable agents' (Giddens 1984: 199) are needed who are able to mobilise consensus and consent among those members. For that to occur, timely access to relevant information about current circumstances, options and likely future outcomes is an influential precondition for arriving at condoned action.

It is not surprising then that data collection for exercising effective governance and the effective governance of data are emerging as twin capabilities fundamental to underwriting the daily exercise of indigenous self-determination and sovereignty for the social good. These entwined issues are examined in the remainder of this chapter. But first it is useful to understand more about the common conditions that have invigorated conversations and initiatives among indigenous peoples about data sovereignty in the four CANZUS countries.

\section{From datum nullius to data sovereignty}

The governance of data - that is, who has the power and authority to make rules and decisions about the design, interpretation, validation, ownership, access to and use of data-has emerged as a site of contestation between indigenous peoples and the colonial settler states within which they reside. A particularly salient concern is the concept of 'data', which is itself a socially constructed field with epistemologically diverse underpinnings and corresponding issues of validity, relevance, application and dissemination (see, for example, Agrawal 1995; Smith 1991ab, 1994; Smylie \& Anderson 2006).

At their most basic, data are simply attributes or properties that represent a series of observations, measurements or facts that are suitable for communication and application (Ellis \& Levy 2012; Bruhn 2014). Data constitute a point-in-time intervention into a flow of information or behaviour - an attempt to inject certainty and meaning into uncertainty. As such, data can be useful for generalising from a particular sample to a wider population or category set, for testing hypotheses, for choosing between options and determining the relationship between particular variables. However, when derived from ethnocentric criteria and definitions, data can also impose erroneous causal connections and simplify social complexity, thereby 
freezing what may be fluid formations in the real world. In their unadorned quantitative form, data are hard-pressed to cope with social and cultural intangibles.

'Data' should also be conceptually distinguished from 'information', which results when people attribute meaning and values to data in a particular context. In intercultural contexts, seemingly objective data and their interpretation as information can become misguided political, policy and ideological instruments. For that reason, both data and information may have limited validity or usefulness when externally imposed as constructions of indigenous behaviours and social formations.

Efforts to permanently settle and control mobile indigenous peoples have been a perennial project of colonial and contemporary nationstates in all four CANZUS countries. Indigenous families were frequently forcibly relocated from their lands, separated from each other and centralised into artificial communities. Their collective rights and self-constructed categories of social organisation were reshaped by colonial frameworks resting on the Western principles and primacy of individual citizenship and assimilation. The scope of the colonial paradigm of 'nullius' has been more broadly applied beyond the legal fiction of terra nullius. It has also purported equivalent fictions about indigenous governance and knowledge systems.

Colonial governments deployed strategies to standardise and simplify the indigenous 'social hieroglyph into a legible and administratively more convenient format' (Scott 1999: 3). Indigenous 'peoples' were enumerated into 'populations' (Taylor 2009); their domestic arrangements and wellbeing were constrained within quantitative datasets and indicators that reflected colonial preoccupations and values. For example, in Australia, the Indigenous logic of family structures, shared parenting and kin relations disappeared under the overwhelming weight of national census statistical analyses (Smith 1991a, 1994; Daly \& Smith 1996). Indigenous economies were relegated to a precapitalist category positioned outside so-called mainstream indicators of what constituted 'economically active work', employment and unemployment and productive development (Smith 1991b). 
In a similar vein, Indigenous modes of governance across Australia were variously portrayed in colonial discourse as a form of gubernare nullius - that is, empty, invisible and unknowable - frozen in an underdeveloped 'primitive' stage of social evolution. From such a standpoint, they were pathologised as being hopelessly dysfunctional and corrupted by kin relationality (Smith 2008). Indigenous knowledge systems in turn were treated as datum nullius - a blank slate on which could be constructed the edifice of a distorting 'colonial archive' (Nakata 2007; see also Pool, this volume).

In all four countries, similar nullius fictions contributed to the imposition of Western modes of democratic governance, the disruption of indigenous leadership networks and the belittling of indigenous systems of authority and knowledge. Collective institutions of governance were overridden and transformed into legal corporations where indigenous governing traditions, roles and responsibilities were curtailed and externally regulated. New categories and institutions of governance - of boards, executives, councillors, voting, representation, democracy and so on-were inserted into the daily fabric of indigenous peoples' lives.

Today, these tools continue to facilitate the neoliberal control and management of indigenous peoples' lives by nation-state governments. It is hardly surprising, then, that there has been a common move by indigenous groups and their leaders over recent decades to reassert their self-determined modes of governance and their self-identified aspirations. However, as indigenous groups begin to replace outsiders' agendas with their own, they are often confronted with the daunting reality that their contemporary governance arrangements have been significantly eroded and that they lack the relevant data on which to make informed decisions and take action.

Over 25 years ago in Australia, the Royal Commission into Aboriginal Deaths in Custody (RCIADIC 1991) recommended that:

When social indicators are to be used to monitor and/or evaluate policies and programs concerning Aboriginal people, their informed views should be incorporated into the development, interpretation and use of the indicators, to ensure that they adequately reflect Aboriginal perceptions and aspirations. (RCIADIC 1991: Recommendation 2:53) 
In the development of future national censuses and other data collection activity covering Aboriginal people, the Australian Bureau of Statistics and other agencies ... ensure that full account is taken of the Aboriginal perspective. (RCIADIC 1991: Recommendation 2:63).

Commonwealth, State and Territory Governments provide access to all government archival records pertaining to the family and community histories of Aboriginal people. (RCIADIC 1991: Recommendation 2:79)

These were groundbreaking recommendations and were asserted in different contexts by indigenous leaders and organisations in each of the CANZUS countries. However, it has become increasingly clear that the process of rebuilding or strengthening indigenous governance is closely aligned with the need to also reassert indigenous peoples' control and interpretation into the colonial data archives, and to produce alternative sources of data that are fit for their contemporary purposes.

It is in this historical context that the concept of data sovereignty has emerged to describe the ability of indigenous peoples to practice self-rule and self-governance when it comes to data and the opening of data, and their capacity to gather and manage data for their own purposes and use.

\section{The indigenous governance challenge}

The international experience of former UN Special Rapporteur on Indigenous Rights James Anaya (Smith 2012) led him to identify three eras in the fight by indigenous peoples for self-determination, with each era having its own discrete governance challenges. These are:

1. the prerecognition era of colonisation with its denial of indigenous sovereign governance

2. the battle for rights and recognition in which indigenous governance solutions focused on political priorities

3. the post-UN Declaration era of governance implementation.

Over the past 40 years, in each of the four CANZUS jurisdictions, a transition has been occurring from the rights battle to the governance and development challenge. Which is not to say that the rights battle has been won, but rather that the progress made on the rights agenda 
has led directly to a critical issue - one captured in Patrick Dodson's comments to an international conference on indigenous peoples (see Smith 2012: 11):

The challenge for traditional owners, like the Yawuru, is how do we, as a people, leverage our native title rights so as to promote our own resilience and reliable prosperity in the modern world.

Arguably, this is the challenge of governance performance and effectiveness - a challenge that has turned out to be a very different task from that of fighting for rights.

Successfully achieving a treaty or land claim, negotiating a resource agreement or implementing an economic initiative invariably requires indigenous people to reassess and restructure their existing governance arrangements. This is because what worked to get them through negotiations is not necessarily what will work to implement the conditions of resulting agreements, claims and treaties. Furthermore, success propels people from thinking about past grievances to thinking about future priorities and how to achieve them.

In addition, there is now an entire generation of young indigenous people whose careers and involvement in indigenous affairs have taken place in the post-land rights, post-treaty and post-settlement environment. Not only does this give them a different viewpoint on history and what is possible, but also they are impatient for strong indigenous governance, for sound decision-making and informed action that will translate the promise of rights into tangible outcomes. From these varied indigenous viewpoints, the collection, ownership, analysis and strategic use of a range of robust data are increasingly recognised as being fundamental to building resilient governance capable of delivering outcomes.

\section{Data for governance}

Effective governance, whether for a small group or a large nation, means being capable of leadership and stewardship, future-oriented planning, problem solving, evaluating outcomes, developing strategies and taking remedial action. To support that suite of governance capabilities, many indigenous groups and their governing bodies are choosing to produce, interpret and manage their own information 
systems and databases (Smith 2002, 2005; Taylor 2005; Taylor et al. 2014). In an age of information overload, this can be a daunting governance task in itself.

As part of designing the methodological and conceptual framework for the conduct of the Australian Indigenous Community Governance (ICG) Research Project, I identified several key dimensions and influential components of indigenous modes of governance-both internal and external (Smith 2005: 23-4). Each of these dimensions is associated with a range of governing capabilities, institutions, structures and practices that can be strengthened and adapted through considered interventions (Dodson \& Smith 2003). For that to happen successfully, various kinds of data and information will be needed about each dimension (Table 7.1).

Table 7.1 Data for building and evaluating indigenous governance arrangements

\begin{tabular}{|l|l|}
\hline Dimensions of governance & Some key items of information/data needed \\
\hline $\begin{array}{l}\text { Cultural geography and } \\
\text { legitimacy }\end{array}$ & $\begin{array}{l}\text { The culturally valued layers and aggregations of social } \\
\text { relations and territorial organisation forming the bases } \\
\text { of group ownership of land and related identities. }\end{array}$ \\
\hline Power and authority & $\begin{array}{l}\text { Sources, scope, composition, social boundaries } \\
\text { and distribution, networks, checks and balances, } \\
\text { accountability, transmission, modes and standards } \\
\text { of exercise. }\end{array}$ \\
\hline Leadership/governors & $\begin{array}{l}\text { Pathways, selection, monitoring, accountability, roles } \\
\text { and responsibilities, standards of conduct, hierarchies, } \\
\text { succession, capacity-building of leaders and decision- } \\
\text { makers (male and female). }\end{array}$ \\
\hline Decision-making & $\begin{array}{l}\text { Processes, mechanisms and rules for, forms of, } \\
\text { consensus orientations, implementation of, free prior } \\
\text { informed consent, social organisation and subsidiarity of. }\end{array}$ \\
\hline Institutional bases & $\begin{array}{l}\text { Standards, measures, structures, purposes, goals, } \\
\text { capacities, policies, actions and outcomes, transparency, } \\
\text { compliance, organisational bases and structure for. }\end{array}$ \\
\hline Strategic direction & $\begin{array}{l}\text { Planning, priorities, strategies for short and long-term } \\
\text { risk management. }\end{array}$ \\
\hline Participation and voice & $\begin{array}{l}\text { Group membership, demographic characteristics, extent } \\
\text { of participation and involvement in decision-making, } \\
\text { elections and voting, communication with members/ } \\
\text { citizens, dispute resolution. }\end{array}$ \\
\hline Accountability & $\begin{array}{l}\text { Rules and norms, mechanisms and procedures for } \\
\text { internal and external controls over corruption and rent- } \\
\text { seeking behaviour. }\end{array}$ \\
\hline
\end{tabular}




\begin{tabular}{|l|l|}
\hline Dimensions of governance & Some key items of information/data needed \\
\hline Resource governance & $\begin{array}{l}\text { Cultural, human, natural, economic, technological, } \\
\text { financial and other resources and assets that indigenous } \\
\text { people need, have access to or control over. Availability, } \\
\text { use and impacts of resources. }\end{array}$ \\
\hline $\begin{array}{l}\text { Governance of (nation-state) } \\
\text { governments }\end{array}$ & $\begin{array}{l}\text { Institutions, structures, values and capacities, powers, } \\
\text { policy and service delivery, funding mechanisms, } \\
\text { accountability mechanisms, communication and } \\
\text { negotiation with. }\end{array}$ \\
\hline Governance environment & $\begin{array}{l}\text { Web of relationships with external parties, wider } \\
\text { operating environment, stakeholder analyses, fiscal flows } \\
\text { and funding, impact of wider regional, state and national } \\
\text { environment, markets. }\end{array}$ \\
\hline Capacity development & $\begin{array}{l}\text { Skills, expertise, knowledge, information, abilities to } \\
\text { build governance, capability gaps between government } \\
\text { rhetoric and on-the-ground reality about what works. }\end{array}$ \\
\hline Governance self-evaluation & $\begin{array}{l}\text { Standards and measures by which governance } \\
\text { 'success' is defined from indigenous and other } \\
\text { perspectives, influential factors, meaningful criteria } \\
\text { and principles for assessing effective and legitimate } \\
\text { indigenous governance. }\end{array}$ \\
\hline
\end{tabular}

Source: The author.

\section{Prioritising data for governance: where to start}

A challenge in indigenous governance more generally is that often it is the case that everything needs work, which sometimes means that little gets done. So what kind of data will support indigenous peoples' purposes of evaluating and strengthening their governing arrangements? Is there a way to think about priority areas for data collection and analysis that would: 1) begin to implement data sovereignty, 2) provide a data foundation on which to build, and 3) move people further down the road towards self-governance based on robust information?

Strengthening and rebuilding governance is a journey. All the issues cannot be addressed at once, and there are no perfect 'good governance' solutions. Rebuilding governance might require immediate substantial changes or small progressive ones. Someone has to lead the way, but it is also critical to keep the nation and community members fully informed, with a voice in decisions. The process of data collection 
may challenge existing vested interests within a community and in the wider external environment. So being inclusive, transparent and consultative promotes credibility and participation in the process. Whatever the initial impetus, data strategies will be more effective and sustainable if the governance problems and solutions are identified by the group or organisation itself.

Governance is about relationships. As a consequence of colonial interventions and violence across the CANZUS countries, one of the very first issues that arises when indigenous people discuss the kind of governance they have or want is the configuration of their own collective cultural identity and internal relationships: Who is the 'self' in their particular mode of self-determination? Who is, and is not, a member? Is the 'self' differently constituted at different societal levels? On whose behalf are leaders and representative organisations governing? These questions go to the heart of self-determined legitimate solutions for governance. To answer them, people often seek out information about their particular cultural geographies and group membership.

Usually such information is not to be found in mainstream data collections and institutions (such as university libraries, government archives, national censuses, sample surveys). Those invariably operate at the level of Western enumeration concepts and categories. Such datasets are rarely available at the level of indigenous culturally based polities (such as nations, governments, regions, communities, local groups, clans and extended families).

Accordingly, a priority data area for governance is to get some hard demographic facts about group membership and relationships that are also linked to landownership. That can include finding out about such things as: what matters to members about their governance as well as their concerns and suggestions; what they think can be done about it; how many members are attending annual general meetings or are involved in selecting or electing leaders; and how many young people are involved in decision-making processes. Such data will reveal a lot about the future demands on governance and services.

Another critical area for early data collection and analysis is governance performance. For example, are decisions and risk assessments routinely informed by relevant sound data? Have decisions over the past year 
been implemented? What are the leadership strengths and gaps? These data will give a better idea of governance effectiveness and future needs. Today, indigenous nations and their organisations are increasingly using computerised systems to keep records of decisions made, allocate responsibility for follow-up action, track outcomes, report back to their governing bodies and deal with any problems.

Data for financial planning and accountability will help a nation or community to understand their overall financial situation as reported, ask the right questions so members can know the true state of their collective finances and make more informed decisions about financial priorities and development options. However, it is important for complex financial and business information to be pulled together into accessible formats for presentation to governing bodies and members.

A cornerstone of collective resilience in times of crisis and rapid change is strong governance built on knowing what you have and using it well. This means having information about the strengths, assets, resources and expertise a nation, community or organisation already has and can bring to bear. Everyone in a group has skills, abilities, knowledge and experience that can be drawn on to strengthen governance and reinforce a shared commitment to rebuilding. An early data collection priority therefore is to document a group's existing infrastructure, technology, funding sources and base, human and cultural capital and natural assets.

While most data are informative, not all data will be fit for indigenous peoples' purposes of assessing and (re)building their governance. On the contrary, when an indigenous governance agenda is imposed from the outside, data needs and the bases for interpretation are also effectively imposed from the outside. This can seriously undermine indigenous self-evaluation of governance and the design of selfdetermined solutions. From this perspective, poor data quality and analyses arguably contribute to poor governance. By contrast, robust culturally informed data used in relevant contexts can serve as a foundation to support more effective and legitimate indigenous governance. 
This suggests the possibility of creating a self-reinforcing system - a 'virtuous' cycle - in which improving the relevance, validity and applicability of data enhances governance, which in turn improves capability for a range of governance responsibilities, including that of collecting and governing data.

\section{Culture-smart information}

In every society there are cultural determinants of what constitutes leadership, decision-making, representation, group membership, participation, legitimacy and accountability. And different behaviours, standards and measures may apply. Serious problems arise when supposedly objective statistics do not adequately reflect these differences. Exacerbating that limitation is the tendency to dismiss as unimportant those processes and behaviours which we do not know how to measure by standard methods. The result is a tyranny of the measureable, which confers power and legitimacy on the thing that is measured. So the production of data for and about governance immediately raises issues of relative power-that is, whose voice is given priority in determining the meaning, validity and values attached to data (see Morphy, this volume)?

Just as governance is a culturally based concept, so, too, are the criteria, indicators and measures used to generate systems of data and information. Hence, in Indigenous Australia, not all information is freely available to everyone within a group. There are influential gender and age dimensions and associated rules around certain restricted forms of information, who owns and can reproduce and authorise information and who has access to it and for what purposes. There is also a hierarchy of value given to different fields of information and knowledge, with certain kinds constituting 'inalienable possessions' passed on from one generation to the next. Information about highvalue things (be they land, sites, names, body designs, songs, stories, knowledge, ritual practices or paraphernalia) becomes imbued with the intrinsic and ineffable identities of their owners, accreted with history, and acts as a repository of collective memories and identities.

As a consequence, authority over particular kinds of indigenous information is distributed across interdependent social layers and polities, establishing a culturally based subsidiarity of information 
and knowledge. Often particular people and subgroups are charged with the transfer of specific areas of knowledge from one generation to another. Such information and things constitute what Radin (1982) and Moustakas (1989: 1185) refer to as rights in cultural 'property for grouphood'. This complex knowledge economy has implications for the collection, digitisation and dissemination of indigenous knowledge (see Nakata \& Langton 2006; Nakata et al. 2008). Furthermore, assessments by indigenous people of the legitimacy of their leaders and governance are sometimes closely linked to their ability to protect and maintain these valued heartlands of cultural information.

These culturally based conditions and practices do not negate the importance of quantitative data for governance performance. Indigenous groups want governance that not only is culturally legitimate, but also has the practical capacity to deliver outcomes. Furthermore, to facilitate free, prior informed consent, people need accurate and relevant information. And local levels of governance require 'the development of local-level data collection, management and reporting systems' (Smith 2002: 18). These various goals depend on having collection, access and use procedures and policies for the governance of both qualitative and quantitative data, supported by technical skills and infrastructure. From this perspective, then, data system priorities and standards should be driven by the strategic priorities of indigenous communities and nations, rather than imposed from the outside via nation-state policies and agendas.

To govern for the future, indigenous people are looking for what I would call 'culture-smart' data-that is, information that can be produced locally, captures local social units, conditions, priorities and concerns and is culturally informed and meaningful. These kinds of data build on existing indigenous capabilities and knowledge, have direct practical application and represent collective identities, rights and priorities. Culture-smart data have greater potential to mobilise support and a mandate from group members, to boost accountability and legitimacy and to improve the quality of actual service deliveryall of which are fundamental ingredients in the practical exercise of sovereignty. 


\section{Governance of data and information}

The ownership of, access to and control over the use of data are governance issues (Nakata \& Langton 2006; Bruhn 2014). Contrary to contemporary Western conceptualisations of corporate governance and 'big data' management systems, indigenous peoples' governance or stewardship of data is not simply about the data. It is about the people who provide and govern an asset that happens to be data. From this perspective, arrangements for the governance of data tend to be assessed by indigenous peoples according to whether they satisfy the spirit and intent of reproducing their culturally based systems of knowledge, alongside delivering on their planning, service-delivery and development aspirations.

Critical functions of governance therefore are the collection and analysis of relevant packages of information that can be communicated effectively to governing bodies, leaders, group members, organisations and external stakeholders. Strong governance creates checks and balances to ensure that data collection supports the priorities of a group or organisation, implements agreed standards for data quality control and works to ensure data are available in a timely way. Ineffective governance of data can lead to uninformed decision-making, low participation by membership, project failures, loss of reputation and credibility and missed development opportunities.

The clear conclusion is that nations, communities and organisations need practically effective governance arrangements to collect and convert relevant and meaningful information into sensible advice and options. Unfortunately, many indigenous groups lack the economies of scale and human capital needed to underwrite the governance of big data systems, especially where data are of varied quality and reliability.

Therefore, to deliver on the promise of culture-smart and relevant information systems, indigenous governance arrangements need to be designed and implemented under a framework of principles and practices that:

- Sets and enforces agreed standards, culturally informed definitions and classification systems for data production, ownership, analysis and administration. 
- Develops and enforces agreed rules, policies and processes around access, dissemination, monitoring, management and review of data, including what kinds of data will not be collected or will have restricted access.

- Identifies and publicises clear cultural rules and protocols with respect to indigenous intellectual property rights, which outline the consents required to access and use high-value cultural information that has been collated.

- Sets out a management structure for data that clarifies the roles, responsibilities and accountabilities of people charged with collecting, analysing, maintaining and communicating data. This includes leaders, executive committees, managers and community members.

- Puts in place user-friendly technologies and infrastructure and member-focused data platforms that include building the capabilities of members to access, interpret, use and maintain their own data.

- Ensures governance arrangements for repatriating and protecting indigenous data property rights are based on the principle of selfdetermination.

When such data governance is in place, indigenous communities and nations will have a more reliable foundation on which to make sound decisions about their overall goals and objectives; what kind of life they want to build; what assets they have or require; what things they want to retain, protect or change; the kind of development they want to promote or reject; and what actions they need to take to achieve those goals (see also FNIGC, Hudson et al., Hudson, Jansen, Yap \& Yu, this volume).

\section{Conclusion}

The concept of data sovereignty has emerged as a particularly salient one for indigenous nations and groups whose sovereignty has been diminished and whose representation within colonial archives has often been maligned. It is a concept that alludes to the promise that self-determination can be put into practical effect by indigenous 
people gathering data that are fit for their own purposes. It also implies having not only a recognised right, but also the local mandate and capacity to produce more meaningful, culture-smart information.

Sovereignty includes being able to design rules for the restriction and opening of data. Open data in the context of indigenous peoples is a double-edged sword. On the one hand, open data could be used to inform development, allocate resources and set a future vision - and to influence wider public opinion and debates. On the other hand, opening up data may be accompanied by concern about protecting indigenous cultural information, rights and intellectual property (see Pool, this volume). Importantly, data sovereignty means taking on a significant responsibility to collect and maintain data that reinforce/ restrict particular collective identities and assist in delivering real improvements in people's circumstances. From this perspective, indigenous governance of data assets is about stewardship for both present and future generations.

Finally, in light of the rapid spread of internet technologies and the globalisation of access (legal and illegal) to information, we must consider the extent to which data sovereignty is facing additional, significant new challenges. Everything seems to be becoming, in one way or another, public data; even the strongest encryptions and firewalls cannot protect modern data systems. But this phenomenon is dependent on certain technologies. Perhaps the next challenge in this arena is for indigenous people to identify whether there are ways to use their own technologies and institutions to protect confidential data - for example, by keeping certain culturally valued or personal data in the form of oral tradition or producing data using indigenous languages. Long-term data protection for indigenous peoples may directly depend on the preservation and transmission of their technologies of language, art and semiotics and the extremely narrow distribution of the knowledge necessary to use those technologies. The narrowness of such distribution perhaps makes this a fragile kind of protection - but, at the very least, as a consequence of considering and making informed decisions about such data challenges, indigenous peoples are effectively acting in sovereign ways. In other words, the very act of designing workable ways of governing data for contemporary purposes, and producing indigenous data representations of collective identity, contributes to constructing self-determination as a current practice rather than an ephemeral future goal. 


\section{References}

Agrawal A (1995). Dismantling the divide between indigenous and scientific knowledge. Development and Change 26(3):413-59.

Bruhn J (2014). Identifying useful approaches to the governance of indigenous data. The International Indigenous Policy Journal 5(2): $1-32$.

Daly A \& Smith DE (1996). The contemporary economic status of Indigenous Australian families. The Australian Journal of Social Issues 31(4):354-75.

de Alcantara $\mathrm{CH}$ (1998). Uses and abuses of the concept of governance. International Social Science Journal 155:105-13.

Dodson M \& Smith DE (2003). Good governance for sustainable development: strategic issues and principles for Indigenous Australian communities, CAEPR Discussion Paper No. 250, Centre for Aboriginal Economic Policy Research, The Australian National University, Canberra.

Ellis T \& Levy Y (2012). Data sources for scholarly research: towards a guide for novice researchers, Graduate School of Computer and Information Sciences, Nova Southeastern University, Fort Lauderdale, Fla., proceedings.informingscience.org/InSITE2012/ InSITE12p405-416Ellis0114.pdf.

Giddens A (1984). The constitution of society, Polity Press, Cambridge.

Moustakas J (1989). Group rights in cultural property: justifying strict inalienability. Cornell Law Review 74:1179-227.

Nakata M (2007). Disciplining the savages: savaging the disciplines, Aboriginal Studies Press, Canberra.

Nakata M \& Langton M (eds) (2006). Australian Indigenous knowledge and libraries, University of Technology, Sydney EPress, Sydney.

Nakata M, Nakata V, Gardiner G \& McKeough J (2008). Indigenous digital collections: an early look at the organisation and culture interface. Australian Academic \& Research Libraries 39(4):223-36. 
Radin MJ (1982). Property for personhood. Stanford Law Review 34:957-1015.

Royal Commission into Aboriginal Deaths in Custody (RCIADIC) (1991). Royal Commission into Aboriginal Deaths in Custody (RCIADIC) national report: overview and recommendations, Commissioner Elliott Johnson, Australian Government Publishing Service, Canberra.

Scott JC (1999). Seeing like a state: how certain schemes to improve the human condition have failed, Yale University Press, New Haven, Conn.

Smith DE (1991a). The cultural appropriateness of existing survey questions and concepts. In Altman JC (ed.), A national survey of Indigenous Australians: options and implications, CAEPR Research Monograph No. 3, Centre for Aboriginal Economic Policy Research, The Australian National University, Canberra.

Smith DE (1991b). Towards an Aboriginal household expenditure survey: conceptual, methodological and cultural issues, CAEPR Discussion Paper No. 10, Centre for Aboriginal Economic Policy Research, The Australian National University, Canberra.

Smith DE (1994). The cross-cultural validity of labour force statistics about Indigenous Australians, CAEPR Discussion Paper No. 69, Centre for Aboriginal Economic Policy Research, The Australian National University, Canberra.

Smith DE (2002). Jurisdictional devolution: towards an effective model for Indigenous community self-determination, CAEPR Discussion Paper No. 233, Centre for Aboriginal Economic Policy Research, The Australian National University, Canberra.

Smith DE (2005). Researching Australian Indigenous governance: a methodological and conceptual framework, CAEPR Working Paper No. 29, Centre for Aboriginal Economic Policy Research, The Australian National University, Canberra. 
Smith DE (2008). Cultures of governance and the governance of culture: transforming and containing Indigenous institutions in western Arnhem Land. In Hunt J, Smith DE, Garling S \& Sanders $\mathrm{W}$ (eds), Contested governance: culture, power and institutions in Indigenous Australia, CAEPR Research Monograph No. 29, Centre for Aboriginal Economic Policy Research, The Australian National University, Canberra.

Smith DE (2012). Common roots, common futures: different pathways to self-determination. An international conversation, conference report, The University of Arizona, Tucson, 20-22 February 2012.

Smylie J \& Anderson M (2006). Understanding the health of indigenous peoples in Canada: key methodological and conceptual challenges. Canadian Medical Association Journal 175(6):602-5.

Taylor J (2005). Capacity building for Indigenous governance: social indicators for Indigenous governance, Paper prepared for the ICG Research Project workshop with WA and Australian governments, Centre for Aboriginal Economic Policy Research, The Australian National University, Canberra.

Taylor J (2009). Indigenous demography and public policy in Australia: population or peoples? Journal of Population Research 26:115-30.

Taylor J, Doran B, Parriman M \& Yu E (2014). Statistics for community governance: the Yawuru Indigenous population survey, Western Australia. The International Indigenous Policy Journal 5(2):1-31. 
This text is taken from Indigenous Data Sovereignty: Toward an agenda, edited by Tahu Kukutai and John Taylor, published 2016 by ANU Press, The Australian National University, Canberra, Australia. 